\title{
Calcification of Falx Cerebri between Male and Female Patients: A Comparative Study
}

\author{
Aahmari A* \\ Department of Radiographer, Radiology, Al-Namas \\ General Hospital, Ministry of Health, Al-Namas City, \\ Saudi Arabia \\ *Correspondling author: Abdulwahab Aahmari, \\ Department of Radiographer, Radiology, Al-Namas \\ General Hospital, Ministry of Health, Al-Namas City, \\ Saudi Arabia
}

Received: May 04, 2021; Accepted: May 28, 2021; Published: June 04, 2021

\begin{abstract}
Objectives: The aim of this paper is to study the calcification that occurs in the inter-hemispheric fissure to compare between male and female patients.

Materials and Methods: The level of density and size of these calcifications were collected and analyzed in 30 patients randomly.

Results: The result of this study showed that there is a relation between falx cerebri and gender since its more common in female patients. The density of the calcifications is higher in males and the calcifications are longer on the AP axis, while the falx cerebri calcifications are wider in the coronal axis in females.

Conclusion: There is a relation between Calcification of falx cerebri and gender. $\mathrm{CT}$

Keywords: Interhemispheric fissure; Falx cerebri; Calcification; Ossification;
\end{abstract}

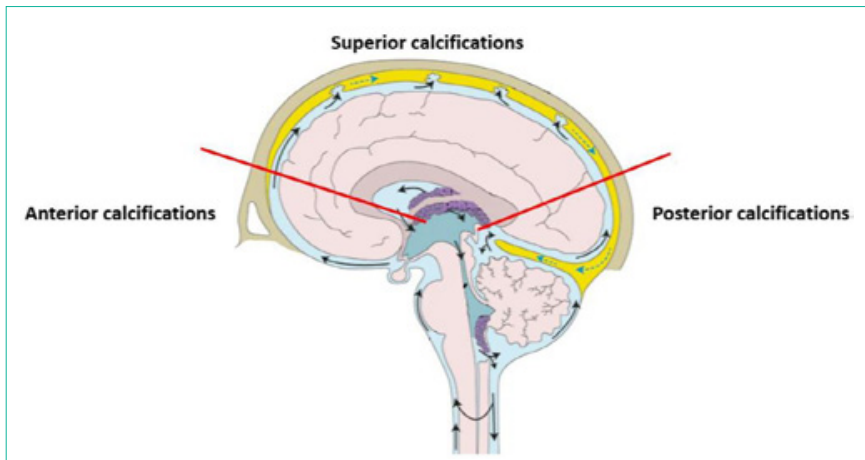

Figure 1: The two red lines separate the 3 regions in which the calcifications will be categorized into. The anterior line is located between the genu and rostrum and the posterior line between the isthmus and splenium of the corpus callosum.

lower $\mathrm{HU}$ and it appears as white ossification or it is the continuation of a skull bone in the inter-hemispheric fissure were included, measured, collected, analyzed, and the result will be provided. The data were analyzed by using Statistical Package for Social Studies (SPSS 20; IBM Corp., New York, NY, USA).

Cases of calcified meningioma and small hematoma in the cerebral fissure were excluded. The null hypothesis of this paper that there is no difference between genders to be more affected by falx cerebri calcifications. The alternative hypothesis is that male patients are more affected by the falx cerebri calcifications. All the patients were given consent forms and notified that their scans will be used in research without using their names or identities. The method and the collected data were approved by the IRB committee to be following the ethical standards.

\section{Results}

The inter-hemispheric classifications are found in 17 female and a score above 300 (Fu, but in this paper, any calcific 


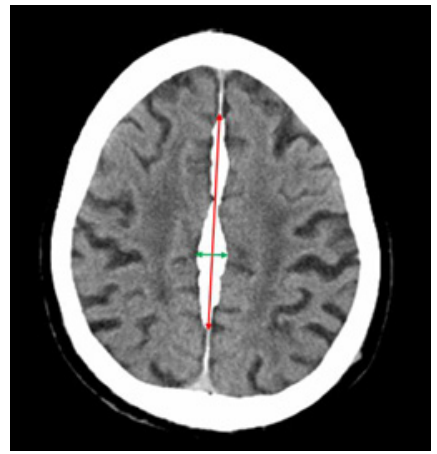

Figure 2: The red arrow represents the length which is taken in (AP direction) and the green arrow represents the width which is taken from (lateral to lateral or coronal direction).

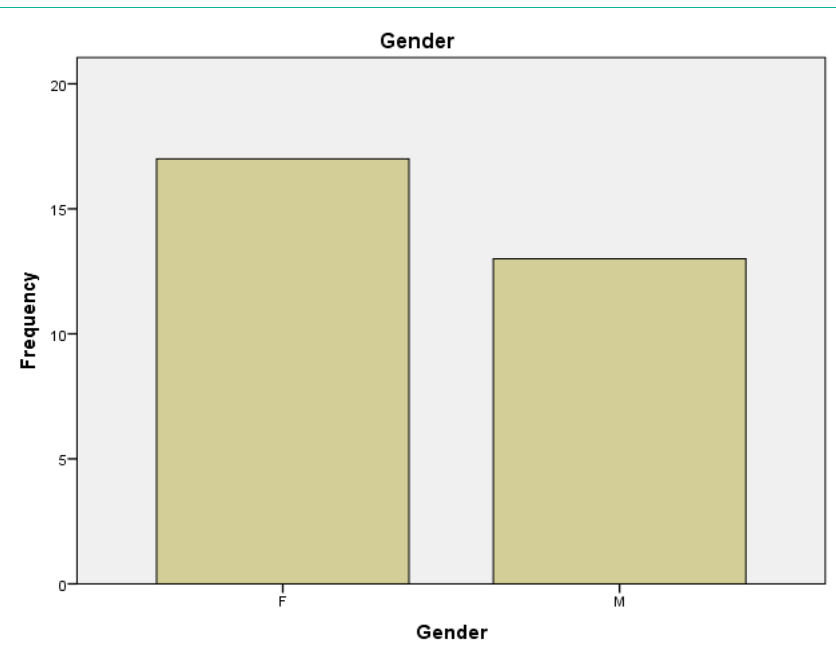

Figure 3: A bar chart shows the distribution of inter-cranial calcifications between male and female.

in 13 male patients which have a percent of $56.7 \%$ to $43.3 \%$ respectively see (Figure 3 ). The average age is 56.53 years, the youngest age found is a 3 -year-old, and the oldest age was recorded is a 100 -year-old.

The average calcification's length (in AP direction) is $32.15 \mathrm{~mm}$, the smallest length of the calcifications is $2.45 \mathrm{~mm}$, and the largest is $487.00 \mathrm{~mm}$. The average width of the calcifications (from lateral to lateral direction) is $6.43 \mathrm{~mm}$, the smallest width is $1.54 \mathrm{~mm}$, and the largest width is $25.07 \mathrm{~mm}$. The average HU recorded for the calcifications is $436.00 \mathrm{~mm}$, the lowest is $85 \mathrm{HU}$, and the highest is $1461.45 \mathrm{HU}$.

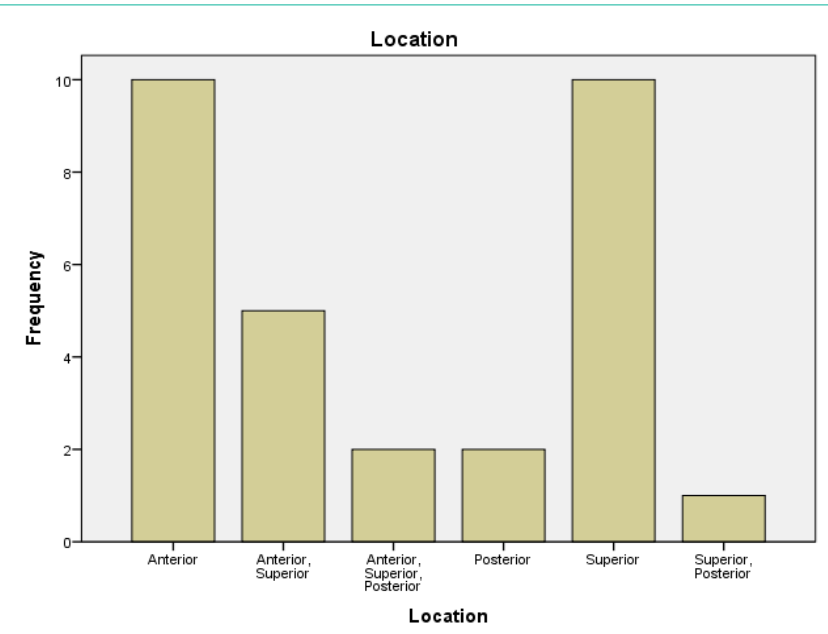

Figure 4: A bar chart shows the distributions of calcifications by the location.

The most common location for calcifications is the anterior region in 10 patients and in the superior region in 10 patients see (Table 1). The second most common calcification is the multiple calcifications in the anterior and superior region of the falx cerebri which was found in 5 patients see (Table 1 and Figure 4).

The most associated condition with falx cerebri calcification was calvarial thickening of the frontal and occipital bones see (Table 2). Multiple calcifications, calcified pineal body, choroid plexus calcifications, and irregular skull shape were repeated findings in patients who have falx cerebri calcifications see (Table 2).

The average length of the inter-hemispheric calcification in males is $55.46 \mathrm{~mm}$ and in females is $14.32 \mathrm{~mm}$ which mean the length of inter-hemispheric calcification is longer in male than female (Table 3). The width of the inter-hemispheric calcification is wider in female more than male which scored 6.88 as mean in females and 5.85 as mean in males see (Table 3). The mean of HU in males is $494.28 \mathrm{HU}$ and in females is $392.64 \mathrm{HU}$ (Table 3).

The size of the calcifications were calculated by adding length and width together for every single case and the mean size of falx cerebri calcification is $38.59 \mathrm{~mm}$. A frequency test was done for the type of the calcifications which showed that type II is the most common type (22 patients/73.3\% of the total sample) and type I was found less than type II (in 8 patients $/ 26.7 \%$ of the total sample).

\section{Discussion}

The inter-hemispheric calcifications were found to be affecting

Table 1: The location of the calcification per patient.

\begin{tabular}{|c|c|c|c|c|c|}
\hline & & Frequency & Percent & Valid Percent & Cumulative Percent \\
\hline \multirow{7}{*}{ Valid } & Anterior & 10 & 33.3 & 33.3 & 33.3 \\
\hline & Anterior, Superior & 5 & 16.7 & 16.7 & 50 \\
\hline & Anterior, Superior, Posterior & 2 & 6.7 & 6.7 & 56.7 \\
\hline & Posterior & 2 & 6.7 & 6.7 & 63.3 \\
\hline & Superior & 10 & 33.3 & 33.3 & 96.7 \\
\hline & Superior, Posterior & 1 & 3.3 & 3.3 & 100 \\
\hline & Total & 30 & 100 & 100 & \\
\hline
\end{tabular}


Table 2: The associated conditions that were found in the patients.

\begin{tabular}{|l|c|c|c|}
\hline \multicolumn{1}{|c|}{ Associated condition } & Male & Female & $\begin{array}{c}\text { Total } \\
\text { Prevalence }\end{array}$ \\
\hline $\begin{array}{l}\text { Calvarial thickening inner table of the skull } \\
\text { (frontal bone) }\end{array}$ & 5 & 5 & 10 \\
\hline $\begin{array}{l}\text { Calvarial thickening inner table of the skull } \\
\text { (occipital bone) }\end{array}$ & 4 & 6 & 10 \\
\hline Multiple calcification (brain parenchyma) & 4 & 3 & 7 \\
\hline Calcified pineal body & 4 & 0 & 4 \\
\hline Irregular skull shape & 3 & 1 & 4 \\
\hline Irregular calcification shape (not round) & 3 & 1 & 4 \\
\hline Senile atrophic changes & 1 & 2 & 3 \\
\hline Choroid plexus calcifications & 3 & 0 & 3 \\
\hline $\begin{array}{l}\text { Skull thickening inner table of the skull } \\
\text { (temporal bone) }\end{array}$ & 1 & 1 & 2 \\
\hline Dural venous sinus thrombosis & 0 & 1 & 2 \\
\hline Centrum ovale infarction & 0 & 1 & 1 \\
\hline Atherosclerotic vertebral arteries & 0 & 1 & 1 \\
\hline Basilar artery calcification & 1 & & 1 \\
\hline $\begin{array}{l}\text { Calvarial thickening outer table (occipital } \\
\text { bone) }\end{array}$ & 0 & 1 & 1 \\
\hline Calcified basal ganglia & 0 & 1 & 1 \\
\hline Cerebellar calcifications & 1 & 0 & 1 \\
\hline $\begin{array}{l}\text { Unilateral elongated occipital horn of the } \\
\text { lateral ventricle }\end{array}$ & 1 & 1 \\
\hline Sinusitis & 1 & 0 & 1 \\
\hline
\end{tabular}

Note: Some patients have 3 findings in the same time or more and some patients do not have any findings beside the falx cerebri calcification on CT scan.

Table 3: The mean in each gender group.

\begin{tabular}{|c|c|c|c|c|c|}
\hline & Gender & N & Mean & Std. Deviation & Std. Error Mean \\
\hline \multirow{2}{*}{ Length } & Male & 13 & 55.4623 & 133.98527 & 37.16083 \\
\cline { 2 - 6 } & Female & 17 & 14.3253 & 30.32843 & 7.35572 \\
\hline \multirow{2}{*}{ Width } & Male & 13 & 5.8515 & 4.10613 & 1.13883 \\
\cline { 2 - 6 } & Female & 17 & 6.8894 & 6.01694 & 1.45932 \\
\hline \multirow{2}{*}{ HU } & Male & 13 & 494.2892 & 409.76971 & 113.64967 \\
\cline { 2 - 6 } & Female & 17 & 392.6441 & 345.11056 & 83.70161 \\
\hline
\end{tabular}

17 females compared to 13 males patient in this study. Similarly, in a cadaveric study who used dissection and $\mathrm{x}$-ray to detect falx cerebri calcifications -which is a weak tool to detect calcifications- had 10 female individuals and 8 male individuals [1]. As well, it's not mentioned in the literature if falx calcifications have a relation with gender or ethnicity or not [1]. In this study, there is a relation between falx cerebri and gender, since it is affecting females more than males.
The HU has no correlation with gender or age, but the mean of $\mathrm{HU}$ in males is 494.28 which is higher than the mean of $\mathrm{HU}$ in females which is 392.64 (Table 3). This finding means that the falx cerebri calcifications are denser in males more than in females. The associated findings which are more common in both gender equally is the calvarial thickening which was found in 20 patients. In some cases, calvarial thickening caused cerebral compression [4]. In addition, calvarial thickening is a sign of more than 20 different diseases and syndromes. Since there was an association between falx cerebri calcifications and calvarial thickening, it could mean that falx cerebri calcifications are associated with the same causes of the calvarial thickening.

There are associated findings that were more common in males more than females which are; calcified pineal body, irregular skull shape, irregular calcification shape (not round), and choroid plexus calcifications see (Table 2). The pineal gland was found to be the most common site of normal/physiological calcification (71.6\%) followed by choroid plexus calcifications (70.2\%) which both are dominant in male patients [5]. The tentorium cerebri is the most common location of calcification in the dural fold followed by falx cerebri [5]. The length and width of the calcifications have a significant correlation with the density of the HU of the calcification.

The location of the calcifications were found in superior region (18 patients), anterior region (17 patients), and posterior region (5 patients). Compared to another study, where the calcifications were found in the anterior region (27 patients), the middle region (7 patients), and the posterior region (2 patients) 3. According to Tsitouridis I. (2006), Type I calcification was found in 6 patients and Type II was found in 34 patients [3], while in this paper type I was found in 8 patients and type II in 22 patients.

As a benchmark, the null hypothesis is rejected based on the result. The alternative hypothesis is partially true and other alternative would be better. However, in a published paper it showed it is affecting females more than males like the findings in this paper, other two papers showed that it is affecting males more than females, and there are 3 papers found no difference between males and females regarding the falx cerebri calcifications see (Table 4).

\section{Conclusion}

The falx cerebri calcifications are more common in female patients based on the number of females patients in this study and previously published studies, but there is no statistical significance of the relationship between gender with the density of the calcification $(\mathrm{HU})$, the size of the calcification, the location of the calcification in

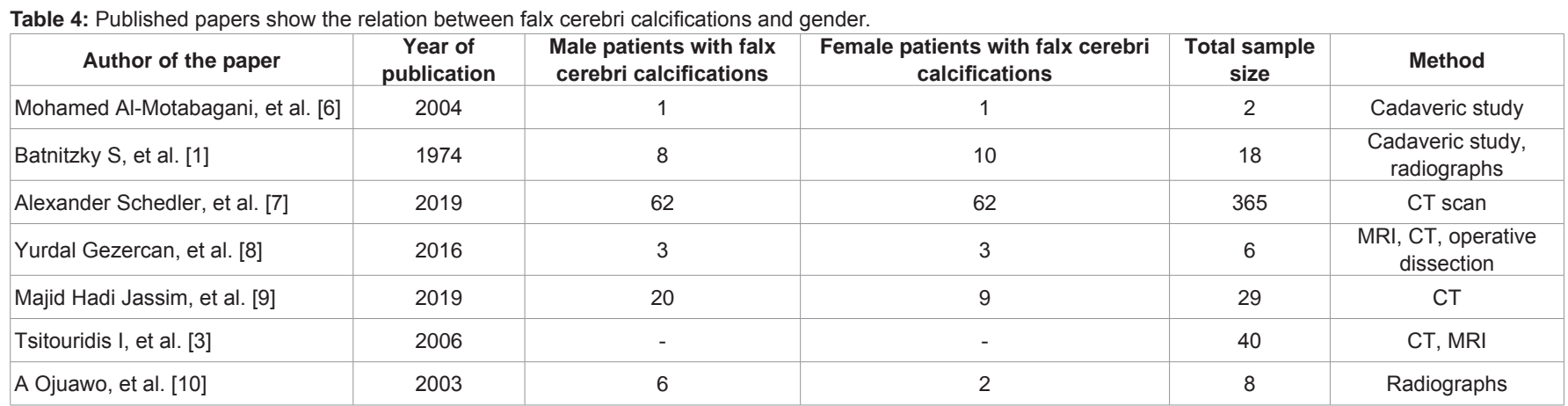


the falx cerebri, or the type of calcification (i.e. type I and II). The density and length of the calcification is higher in males on the AP axis, while is wider in the coronal axis in females. The falx cerebri is associated with clavarial thickening which could cause cerebral compression.

\section{References}

1. Batnitzky S, Powers JM, Schechter MM. Falx "calcification"- does this exist? Neuroradiology. 1974; 7: 255-260.

2. Klintworth GK. The comparative anatomy and phylogeny of the tentorium cerebelli. The Anatomical record. 1968; 160: 635-641.

3. Tsitouridis I, Natsis K, Goutsaridou F, Tsitouridis K, Tarazi L, Chondromatidou $\mathrm{S}$, et al. Falx Cerebri Ossification: CT and MRI Evaluation. The neuroradiology journal. 2006; 19: 621-628.

4. Ooi CP, Mustafa N, Kew TY. Communicating Hydrocephalus in a Case of Long-Term Primary Hyperparathyroidism. Journal of the ASEAN Federation of Endocrine Societies. 2018; 33: 49.
5. Saade C, Najem E, Asmar K, Salman R, El Achkar B, Naffaa L. Intracranial calcifications on CT: an updated review. Journal of radiology case reports. 2019; 13: 1.

6. Al-Motabagani M, Haroun $\mathrm{H}$, Meguid EA. Calcification and ossification of the convexity of the falx cerebri and related subdural space in human cadavers. Neurosciences Journal. 2004; 9: 261-264.

7. Schedler A, Deutschmann H. Falx cerebri Calcifications and Ossifications in CT Scans - A Data Collection on Frequency, Position and Size. European Journal of Osteopathic Research, 2019; 1: 1-7.

8. Gezercan $Y$, Acik V, Çavuş G, Ökten Al, Bilgin E, Millet H, et al. Six different extremely calcified lesions of the brain: brain stones. Springer Plus. 2016; 5: $1-0$.

9. Jassim MH, George NT, Jawad MM. Radiographic Anatomical Study of Intracranial Calcifications in Patients underwent Computerized Tomography Imaging. 2019.

10. Ojuawo A, Nzeh DA, Salisu A. Calcification of Falx Cerebri in childhood: normal variant or a pathological entity. Sahel Medical Journal. 2003; 6: 40-43. 